\title{
Antifouling Ability of Hydrophilic PVDF-TiO 2 membrane Evaluated by Critical Flux and Threshold Flux
}

\author{
Wanying $\mathrm{Xie}^{1}, J i \mathrm{Li}^{1}$, Feiyun Sun ${ }^{1, *}$, and Wenyi Dong ${ }^{1}$ \\ ${ }^{1}$ Shenzhen Key Laboratory of Water Resource Utilization and Environmental Pollution Control, \\ Harbin Institute of Technology, Shenzhen, Guangdong Province, 518055, China
}

\begin{abstract}
The PVDF flat-membrane was modified by hydrophilic nano$\mathrm{TiO}_{2}$, which blending by ultrasonication and mechanical stirring pretreatment in phase inversion method. To evaluate the permeate productivity and anti-fouling capacity of protein solution, both the critical flux $\left(\mathrm{J}_{\mathrm{CW}}\right)$ and threshold flux $\left(\mathrm{J}_{\mathrm{TH}}\right)$ of PVDF and $\mathrm{PVDF}-\mathrm{TiO}_{2}$ membrane were firstly measured by Advanced Constant Pressure-step Method in cross-flow filtration apparatus. Some evaluation indicators were utilized to analyze the results, such as Flux vs. Time and TMP vs. Time Curves, flux decline rate $(\mathrm{dFlux} / \mathrm{dt})$ and TMP-Fluxave curve. Two type fluxes were compared, results exhibited that hydrophilic $\mathrm{PVDF}^{-\mathrm{TiO}_{2}}$ modified membrane possessed a higher level of both $\mathrm{J}_{\mathrm{CW}}$ and $\mathrm{J}_{\mathrm{TH}}$ and better antiprotein fouling ability after testing by Advanced Constant Pressure-step Method.
\end{abstract}

\section{Introduction}

Membrane separation technology was widely used in both water and wastewater treatment, especially for pressure-driven membranes which consisted of four types, porous micro-filtration (MF) or ultra-filtration membranes (UF), or dense nano-filtration (NF) or reverse osmosis (RO) membrane [1]. For porous MF and UF, they were gradually accepted in practical application, due to low-pressure and energy consumption. During practical filtration process, reaction of membrane and contaminants occurred by physical, chemical or biological effects, easily leading to fouling problems limited the application scope. Fouling problem of UF had become one research hotspot. There were three ways to solve the aforementioned problems, treatment of feeds [2], hydrophilic modification of membrane [3], and operation control by critical flux (CF) and threshold flux (TF) [4]. The first route was achieved by extra auxiliary methods, and the latter two routes did not require additional cost investments.

In last decades, various novel hydrophilic additives were attractive for UF membrane fabrication, owing to some advantages, such as rich hydrophilic functional groups and brilliant modification performance [5]. As compared to carbon nanotube [6] and graphene oxide [7], inorganic metal-based oxide was seemingly more available by commercial

* Corresponding author: sun fy@hit.edu.cn 
purchased or self-preparation. Except for $\mathrm{Al}_{2} \mathrm{O}_{3}$ [8], $\mathrm{Ag}$ [9], $\mathrm{SiO}_{2}$ [10] and so forth, nano $\mathrm{TiO}_{2}$ had attracted lots attention because of high hydrophilicity of less toxicity which commonly used in UF modification $[11,12]$.

For operation control, CF or TF operation was often realized by no or low fouling rate, to obtain a less cleaning frequency and longer membrane life in practical significance [13]. After the CF concept proposed in 1995 [14], some researchers found that ideal state of CF, no fouling, might be in very low flux level or did not exist, especially the composition of feeds was complicated [15]. Then, a mild concept of low fouling rate operation named TF, was put forward in 2011 [4]. References investigation showed four major research directions of $\mathrm{CF} / \mathrm{TF}$ operation, the existence [16], new measuring methods [17], the practical significance [18], and the relationship of operation and fouling [19].

Regarding to hydrophilic modified UF membrane, particularly of nano- $\mathrm{TiO}_{2}$ modification, some research gaps put in an appearance. Did the ideal CF operation of modified membrane exist or not. And did the modified membrane had a higher CF and TF level to promote productivity, when it owned a better anti-fouling ability. The purpose of this study was to give better understanding on the anti-fouling capacity of nano- $\mathrm{TiO}_{2}$ modified UF membrane, from $\mathrm{CF}$ and TF perspective. For this, one modified membrane was fabricated by PVDF polymer and nano- $\mathrm{TiO}_{2}$ particle with assist of novel promote pretreatment. The CF and TF values of PVDF and modified $\mathrm{PVDF}^{-\mathrm{TiO}_{2}} \mathrm{membranes}$ were firstly measured by Advanced Constant Pressure-step Method. Fouling behavior of two PVDF membranes were analyzed by fouling resistance.

\section{Materials and Measurements}

\subsection{Fabrication of pristine and modified membranes}

Both pristine PVDF and PVDF-TiO 2 membrane were fabricated by phase inversion method which clearly described in our previous study [20]. Pristine PVDF membrane was made with weight ratio of PVDF : PVP : DMAc $=19: 1.3: 79.7$, and $\mathrm{PVDF}_{-\mathrm{TiO}}$ membrane with weight ratio of nano-TiO 2 : PVDF : PVP : DMAc=1:19:1.3:78.7. The nano- $\mathrm{TiO}_{2}$ was added into DMAc solvent with direct ultrasonication pre-treatment for $1 \mathrm{~h}$, the mixture was kept for $25^{\circ} \mathrm{C}$ by constant temperature circulating water tank. The direct ultrasonication was realized by Cell disruption instrument which named new model Ultrasonic Processor (FS450, China).

Then, PVDF polymer and PVP were added into mixture for mechanical stirring $(24 \mathrm{~h})$ and statically placed in water bath at $55^{\circ} \mathrm{C}(24 \mathrm{~h})$ to finish degassing stage. Certain amounts of casting solution was poured onto clear glass and then casted by thin-film casting doctor blade $(\sim 200 \mu \mathrm{m})$. Certain volume of deionized water was put as coagulation bath to complete the phase inversion process. The pristine membrane was marked as PVDF, and the modified membrane was marked as PVDF-TiO $2(\mathrm{MSU} 2)$.

\subsection{Filtration set-up and determination procedures}

One cross-flow filtration set up was used, three sensors were put near influent and effluent position to measure real-time pressure. The feeds was protein solution with bovine serum albumin concentration of $30 \mathrm{mg} / \mathrm{L}$, and cross-flow velocity was $15 \mathrm{~cm} / \mathrm{s}$. The bovine serum albumin was measured by ultraviolet radiation spectrophotometry at a $\lambda$ of $280 \mathrm{~nm}$. The effective area of membrane cell was $42 \mathrm{~cm}^{2}$, and membrane was compacted at 2 bar for $20 \mathrm{~min}$ before $\mathrm{CF}$ and TF testing. 
Based on the strict concept of CF, Field [14] proposed two types, one was the strong form $\left(\mathrm{J}_{\mathrm{SW}}\right)$ corresponding to feed solution were pure water, another one was the weak form $\left(\mathrm{J}_{\mathrm{CW}}\right)$ corresponding to feeds consisted of water and foulants. For the concern of antifouling ability evaluation, only $\mathrm{J}_{\mathrm{CW}}$ was measured in our study, which tested by the Advanced Constant Pressure-step Method. This method [21] applied the TMP up to a maximum TMP and back analogous to the initial TMP step (Fig. 1(a)). The upping TMP step named as X, and the initial TMP step named as $1-\mathrm{X}$. The operating order was step $1 \rightarrow$ step $2 \rightarrow$ step $1-2 \rightarrow$ step $3 \rightarrow$ step $1-3 \rightarrow \cdots$. For instance, fouling occurred at step 4 and permeate flux decline was observed here, revealing that the critical flux was situated between step 3 and step 4 . At same time, the permeated flux wouldn't be same at step 1-3 and step 1-4. It meant the critical TMP should be below step 4, and the critical flux should be measured at the corresponding critical TMP. If no fouling occurred between step 3 and step 4, the permeated flux of those two steps shouldn't be decreased with filtration time and it also should be same at step 1-3 and step 1-4.

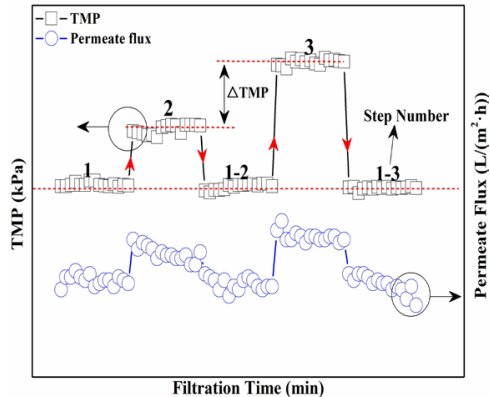

(a)

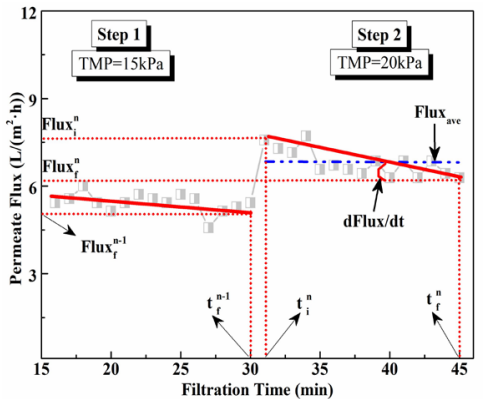

(b)

Fig. 1. The (a) Measurement Procedures and (b) Evaluation Indicators of the Advanced Constant Pressure-step Method in Our Study.

The evaluation indicators of the Advanced Constant Pressure-step Method was shown in Fig. 1(b). The ideal CF was corresponding to no fouling, thus the permeate flux should keep same with no decline and dFlux/dt should be zero. The dFlux/dt was permeate flux decline rate in one pressure step, which equaled to the slope $(k)$ of permeate flux curve (Equation (1)). The Flux $x_{\text {ave }}$ meant the average flux level in one pressure step, which was calculated by average value collected one time per minute in Equation (2). The TF could be estimated by dFlux/dt kept for low value.

$$
\operatorname{Flux}(\mathrm{t})=k \times \mathrm{t}+\mathrm{b}
$$

Where, Flux(t) was the real-time permeate flux collected by electronic balance $\left(\mathrm{L} /\left(\mathrm{m}^{2} \cdot \mathrm{h}\right)\right)$, and $\mathrm{t}$ was the filtration time $(\mathrm{min}), k$ was the slope of fitting linear, $\mathrm{b}$ was one constant.

$$
\text { Flux }_{\text {ave }}=\sum\left(\text { Flux }_{\mathrm{i}}^{\mathrm{n}}+\cdots+\text { Flux }_{\mathrm{f}}^{\mathrm{n}}\right) / 15
$$

Where, Flux ${ }_{i}^{n}$ was the initial flux at pressure step n, and Flux ${ }_{f}^{n}$ was the final flux at pressure step n, 15 was the collected times at one pressure step.

\subsection{Fouling resistance}

After measuring $\mathrm{J}_{\mathrm{CW}}$ and $\mathrm{J}_{\mathrm{TH}}$, the fouling resistance was calculated by resistance-inseries model put in Equation (3) [22]. Where, the J was permeate flux, the $\triangle \mathrm{P}$ was the 
pressure average value in one step, the $\mu$ was permeate viscosity of water at $25{ }^{\circ} \mathrm{C}$, and $\mathrm{R}_{t}$ was the total fouling resistance. $R_{t}$ was also the sum of $R_{m}, R_{c}$ and $R_{f}$. The $R_{m}$ was intrinsic resistance related to membrane structure and characterization. The $R_{c}$ was the gel or cake layer resistance formed by foulants concentration polarization and precipitation, belonged to reversible resistance removed by physical cleaning that fouled membrane was flushed with tap water for $5 \mathrm{~min}$ of each side. The $\mathrm{R}_{\mathrm{f}}$ was the adsorption or blockage resistance formed by foulants adsorption into membrane surface or inside pores, which belonged to the irreversible fouling.

$$
J=\Delta P /\left(\mu \times R_{t}\right)=\Delta P /\left(\mu \times\left(R_{m}+R_{c}+R_{f}\right)\right)
$$

\section{Results and discussion}

\subsection{Critical flux estimation}

\subsubsection{The Flux vs. Time and TMP vs. Time Curves}

The PVDF and PVDF-TiO 2 (MSU2) had similar protein rejection of nearly $60 \%$ $(\mathrm{BSA}=500 \mathrm{mg} / \mathrm{L})$ but different pure water flux level of $50.96 \pm 8.53$ and $117.95 \pm 8.96$ $\left(\mathrm{L} /\left(\mathrm{m}^{2} \cdot \mathrm{h}\right)\right.$, respectively. During Advanced Constant Pressure-step Method, the pressure-step was alternatively increased and then decreased to initial level, which was easily to observe flux decline behavior especially when $J$ was exceeded than $J_{C W}$. The Flux vs. Time and TMP vs. Time Curves (FT-TT curves) was shown in Fig. 2. The flux began to decrease at step 2 of PVDF and at step 3 of $\mathrm{PVDF}_{-\mathrm{TiO}_{2}}(\mathrm{MSU} 2)$ membrane. Protein fouling happened from $15 \mathrm{kPa}$ to $20 \mathrm{kPa}$ for PVDF and from $20 \mathrm{kPa}$ to $25 \mathrm{kPa}$ for PVDF-TiO (MSU2)

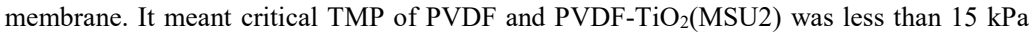
and $20 \mathrm{kPa}$, respectively, which same with the estimation by the dFlux/dt discussed in Fig. 3 . However, because of the instrument limitation we couldn't measure a lower TMP value less than $15 \mathrm{kPa}$, thus the ideal $\mathrm{J}_{\mathrm{CW}}$ of PVDF was not exist and $\mathrm{J}_{\mathrm{CW}}$ of PVDF-TiO $\mathrm{P}_{2}(\mathrm{MSU} 2)$ was exist based on the direct observation. The $\mathrm{J}_{\mathrm{CW}}$ of PVDF and PVDF-TiO $\mathrm{P}_{2}(\mathrm{MSU} 2)$ were $<5.43$ and $16.92\left(\mathrm{~L} /\left(\mathrm{m}^{2} \cdot \mathrm{h}\right)\right.$, respectively.

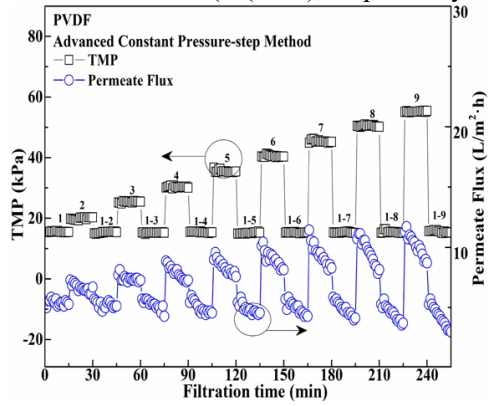

(a)

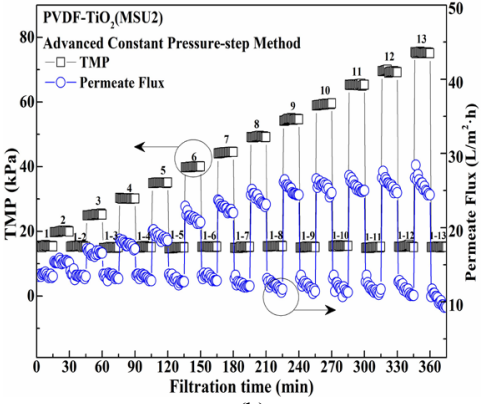

(b)

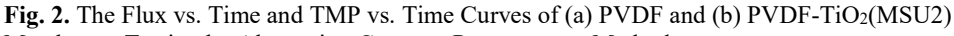
Membrane, Testing by Alternating Constant Pressure-step Method

\subsubsection{The $d$ Flux/dt}


Additionally, the $\mathrm{J}_{\mathrm{CW}}$ could be estimated by dFluxt/dt equalled to zero, which was demonstrated in Fig. 3. It was clearly that no zero dFlux/dt of both TMP ascending phase and relaxation phase was found, which might related to instrument precision and high accuracy required for operation. Depending on the $\mathrm{dFlux} / \mathrm{dt} \approx 0$ reflected no fouling occurred, the $\mathrm{J}_{\mathrm{CW}}$ was estimated as following. For PVDF membrane, when TMP step raised from step 1 to step 2, the dFlux/dt decreased to less than -0.05 , which showed the irreversible fouling occurred. And for PVDF-TiO 2 (MSU2), when step 1 raised TMP to step 2, the dFlux/dt seemed remained near zero. When step 2 decreased to step 1-2, the dFlux/dt decreased to near -0.05 , which illustrated that fouling occurred between step 1 and 2 , then showed at step 1-2 due to fouling hysteresis effect. Therefore, based on the result obtained by $\mathrm{dFlux} / \mathrm{dt}$, the critical TMP of PVDF and PVDF-TiO ${ }_{2}(\mathrm{MSU} 2)$ was less than and equal to $15 \mathrm{kPa}$, their $\mathrm{J}_{\mathrm{CW}}$ were $<5.43$ and $13.88 \mathrm{~L} /\left(\mathrm{m}^{2} \cdot \mathrm{h}\right)$, respectively.

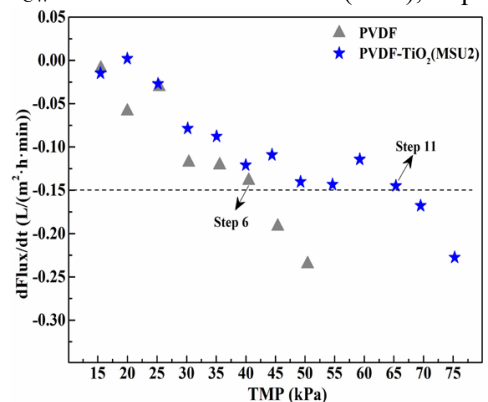

(a)

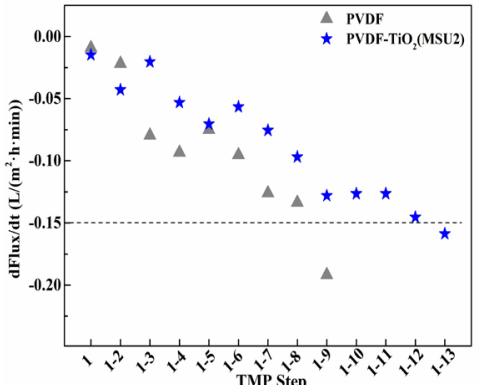

(b)

Fig. 3. The dFlux/dt of PVDF and PVDF-TiO 2 (MSU2) Membrane at (a) TMP ascending phase and (b) TMP relaxation phase by Advanced Constant Pressure-step Method

\subsubsection{The TMP-Fluxave Curves}

The $\mathrm{J}_{\mathrm{CW}}$ also could been evaluated by the TMP-Flux $\mathrm{ave}_{\mathrm{ave}}$ curve, according to the Espinasse's studied on the $\mathrm{J}_{\mathrm{CW}}$ measured by Alternating Constant Pressure-step Method [23]. Set as an example, the first three TMP step of PVDF membrane was step $1 \rightarrow$ step $2 \rightarrow$ step $1-2$, i) if the reversible fouling formed between step 1 and step 2 which could be removed by hydraulic scour of cross flow, the Flux ave of step 1-2 should be close enough to it at step 1, the Flux ave of first three TMP steps should be fitted in linear; ii) or if irreversible fouling formed between step 1 and step 2 which couldn't been removed by cross flow, the Flux $_{\text {ave }}$ of step 1-2 would be less than it of step 1, and this would not continue to be linear relationship. For PVDF, from step 1 to step 1-2, the Flux ave was 5.43, 6.66 and 5.26 $\mathrm{L} /\left(\mathrm{m}^{2} \cdot \mathrm{h}\right)$, and the $\mathrm{R}^{2}$ of fitting linear was 0.9915 which displayed that only reversible fouling formed between 15 and $20 \mathrm{kPa}$. When TMP raised to step 3 then back to step 1-3, the first five points of the TMP-Flux $x_{\text {ave }}$ curve would not maintain in linear, because the $\mathrm{R}^{2}$

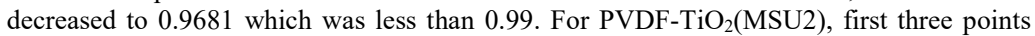
from step 1 to step 1-2 could be in linear due to the $\mathrm{R}^{2}$ was 1 . And it same to PVDF, the linear could not keep until step 3, owning to the $\mathrm{R}^{2}$ decreased to 0.9867 . Herein, the critical TMP of PVDF and PVDF-TiO ${ }_{2}$ (MSU2) were same of $20 \mathrm{kPa}$ at step 2, and the $\mathrm{J}_{\mathrm{CW}}$ were 6.66 and $15.39 \mathrm{~L} /\left(\mathrm{m}^{2} \cdot \mathrm{h}\right)$, respectively. 


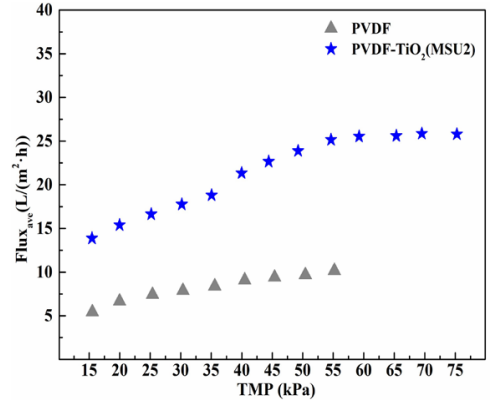

(a)

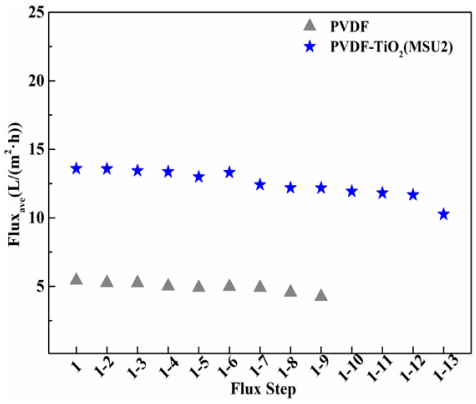

(b)

Fig. 4. The TMP-Fluxave curve of PVDF and PVDF-TiO 2 (MSU2) Membrane at (a) TMP ascending phase and (b) TMP relaxation phase by Advanced Constant Pressure-step Method

\subsection{Threshold flux estimation}

Relying on the TF concept put by Field [4], the fouling rate between low and high fouling region was the key-point. According to the dFlux/dt (Fig. 3), we found that dFlux/dt of two membranes were decreased with TMP increased, then it seemly kept for one pseudosteady state in few steps and dropped dramatically. It looked like $\mathrm{dFlux} / \mathrm{dt}=-0.15$ was one demarcation, when dFlux/dt was less than -0.15 , the dFlux/dt jump appeared and started to drop dramatically. We used this dFlux/dt jump to differentiate low and high fouling region. Therefore, the threshold TMP of PVDF and PVDF-TiO 2 (MSU2) was 40 and $65 \mathrm{kPa}$, and the $\mathrm{J}_{\mathrm{TH}}$ were 9.08 and $25.60 \mathrm{~L} /\left(\mathrm{m}^{2} \cdot \mathrm{h}\right)$.

\subsection{Comparison of $\mathrm{J}_{\mathrm{CW}}$ and $\mathrm{J}_{\mathrm{TH}}$ of PVDF and PVDF-TiO ${ }_{2}$ (MSU2)}

On the basis of previous results, the summary of PVDF and PVDF-TiO 2 (MSU2) were listed in Table 1. When feeds was protein solution, the $\mathrm{J}_{\mathrm{CW}}$ and $\mathrm{J}_{\mathrm{TH}}$ of PVDF and PVDF$\mathrm{TiO}_{2}$ (MSU2) did exist. The critical pressure of PVDF was $<15 \sim 20 \mathrm{kPa}$, the $\mathrm{J}_{\mathrm{CW}}$ was $<$ 5.43 6.66 L/( $\left.\mathrm{m}^{2} \cdot \mathrm{h}\right)$. And for PVDF-TiO ${ }_{2}$ (MSU2), the critical pressure was $15 \sim 20 \mathrm{kPa}$, but $\mathrm{J}_{\mathrm{CW}}$ was improved to $13.88 \sim 16.92 \mathrm{~L} /\left(\mathrm{m}^{2} \cdot \mathrm{h}\right)$. The threshold pressure of PVDF and PVDF$\mathrm{TiO}_{2}$ (MSU2) was 40 and $65 \mathrm{kPa}$, respectively, and their $\mathrm{J}_{\mathrm{TH}}$ were 9.08 and $25.6 \mathrm{~L} /\left(\mathrm{m}^{2} \cdot \mathrm{h}\right)$. The hydrophilic modified membrane had 2 or 3 times of both $\mathrm{J}_{\mathrm{CW}}$ and $\mathrm{J}_{\mathrm{TH}}$ than PVDF membrane, no matter it was evaluated by which indicators. It was inferred that adding nano- $\mathrm{TiO}_{2}$ was benefit for enhancing productivity of PVDF membrane, when operating at $\mathrm{J}_{\mathrm{CW}}$ condition. At same time, hydrophilic modified membrane was surmised brilliant antiprotein fouling ability, when operating at threshold pressure condition it had higher $\mathrm{J}_{\mathrm{TH}}$.

Table 1. The summary of $\mathrm{J}_{\mathrm{CW}}$ and $\mathrm{J}_{\mathrm{TH}}$ evaluated by different indicators

\begin{tabular}{ccccccc}
\hline Membrane & $\begin{array}{c}\text { Critical } \\
\text { Pressure }(\mathrm{kPa})\end{array}$ & $\begin{array}{c}\mathrm{J}_{\mathrm{CW}} \\
\left(\mathrm{L} /\left(\mathrm{m}^{2} \mathrm{~h}\right)\right)\end{array}$ & $\begin{array}{c}\text { Evaluation } \\
\text { indicator }\end{array}$ & $\begin{array}{c}\text { Threshold } \\
\text { Pressure }(\mathrm{kPa})\end{array}$ & $\begin{array}{c}\mathrm{J}_{\mathrm{TH}} \\
\left(\mathrm{L} /\left(\mathrm{m}^{2} \mathrm{~h}\right)\right)\end{array}$ & $\begin{array}{c}\text { Evaluation } \\
\text { indicator }\end{array}$ \\
\hline \multirow{3}{*}{ PVDF } & $<15$ & $<5.43$ & FT-TT curve & & & $\mathrm{dFlux} / \mathrm{dt}<$ \\
& $<15$ & $<5.43$ & $\begin{array}{c}\mathrm{dFlux} / \mathrm{dt} \approx 0 \\
\text { TMP-Flux }\end{array}$ & 40 & 9.08 & -0.15 \\
\hline PVDF-TiO $_{2}$ & 20 & 6.66 & & & \\
$($ MSU2 $)$ & 15 & 16.92 & FT-TT curve & & & $\mathrm{dFlux} / \mathrm{dt}<$ \\
& 20 & 15.88 & dFlux/dt $\approx 0$ & 65 & 25.6 & -0.15 \\
\hline
\end{tabular}




\subsection{Fouling mechanism}

The fouling resistance of $R_{t}, R_{c}$ and $R_{f}$ was shown in Fig. 5. For PVDF-TiO 2 (MSU2) at $J_{C W}$, the reversible fouling $R_{c}$ close to $1 \%$ of the $R_{t}$, which could be neglected. However for PVDF membrane, the irreversible fouling $\mathrm{J}_{\mathrm{f}}$ could not been ignored at $\mathrm{J}_{\mathrm{CW}}$, and it was increased at $\mathrm{J}_{\mathrm{TH}}$ level. It was indicated that ideal status of critical flux condition was not found, but the operating results of PVDF- $\mathrm{TiO}_{2}$ (MSU2) was close to it. It was probably due to the irreversible protein contamination occurred easily of hydrophobic PVDF, the ideal $\mathrm{J}_{\mathrm{CW}}$ was rather small and not detected in our study because instrument limitation. The antiprotein fouling ability of PVDF-TiO $\mathrm{T}_{2}(\mathrm{MSU} 2)$ was enhanced effectively when nano- $\mathrm{TiO}_{2}$ was added, the $\mathrm{J}_{\mathrm{CW}}$ level was improved and could be detected.

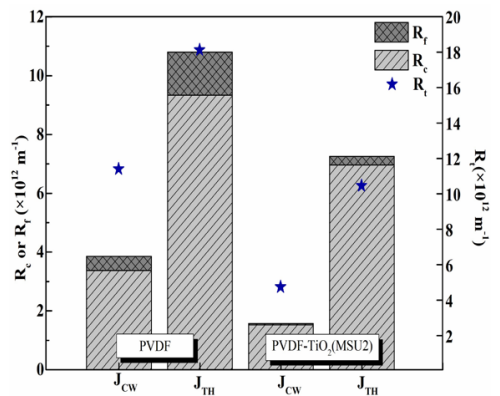

Fig. 5. The fouling resistance of PVDF and PVDF-TiO $2(M S U 2)$ Membrane at $J_{C W}$ and $J_{T H}$.

When flux increased to $J_{T H}$, the $R_{t}, R_{c}$ and $R_{f}$ of two membranes were increased with different degree, especially for PVDF. It attributed to the driven force was higher than that at $\mathrm{J}_{\mathrm{CW}}$, the shear force provided by cross-flow was weaker than protein sedimentation effect, so that concentration polarization layer or pore blockage might formed quickly at threshold TMP. For modified PVDF-TiO 2 (MSU2) membrane, the increased degree of Rc was higher than that of PVDF, due to the threshold TMP was $65 \mathrm{kPa}$ which higher than $30 \mathrm{kPa}$ of PVDF. At same time, no matter at flux level of $\mathrm{J}_{\mathrm{CW}}$ or $\mathrm{J}_{\mathrm{TH}}, \mathrm{R}_{\mathrm{t}}$ of PVDF-TiO $\mathrm{P}_{2}(\mathrm{MSU} 2)$ was smaller than that of PVDF membrane, which illustrated that fouling degree was severer of PVDF. In brief, it was evidently that hydrophilic modification by nano- $\mathrm{TiO}_{2}$ was profit to alleviate protein fouling at permeate flux level of both $\mathrm{J}_{\mathrm{CW}}$ and $\mathrm{J}_{\mathrm{TH}}$.

\section{Conclusion}

When feed solution was protein, the critical flux and threshold flux of PVDF and hydrophilic modified PVDF-TiO 2 (MSU2) were successfully evaluated by the Advanced Constant Pressure-step Method depending on some indicators. As compared to PVDF, the PVDF-TiO 2 (MSU2) owned greater value at both $\mathrm{J}_{\mathrm{CW}}$ and $\mathrm{J}_{\mathrm{TH}}$ which easily guaranteed the productivity at operating optimization. Additionally, the nano- $\mathrm{TiO}_{2}$ was helpful to alleviate the irreversible fouling degree of PVDF membrane at $\mathrm{J}_{\mathrm{CW}}$ and $\mathrm{J}_{\mathrm{TH}}$, especially decreasing the $\mathrm{R}_{\mathrm{f}}$ of PVDF-TiO ${ }_{2}$ (MSU2) at $\mathrm{J}_{\mathrm{CW}}$ level which leading the operation close to ideal status of critical flux.

\section{Acknowledgement}


This work was financially supported by the Shenzhen Science and Technology Funding Project [grant number JSGG20170414101900541 and JCYJ20170816102318538]; the National Natural Science Foundation of China [grant numbers 51678183, 51408149] and the Project supported by Guangdong Natural Science Foundation [grant number 2017A030313285].

\section{References}

1. Bruggen V. d. B., Vandecasteele C, Gestl T. V., Doyen W., Leysen R., Environ. Prog. 22, 1 (2003)

2. Gao W., Liang H., Ma J., Han M., Chen Z., Han Z., Li G., Desalination, 272, 1-3 (2011)

3. Lalia, B.S., Kochkodan V., Hashaikeh R., Hilal N., Desalination, 326, 77-95 (2013)

4. Field, R.W., Pearce G.K., Adv Colloid Interface Sci. 164,1-2 ( 2011)

5. Nasreen S.A.A.N., Sundarrajan S., Syed N.S.A., Balamurugan R., Ramakrishna S., Polym. J. 46, 3 (2013)

6. Yang X., He Y., Zeng G., Chen X., Shi H., Qing D., Li F., Chen Q., Chem. Eng. J. 321, 245-256 (2017)

7. Joshi R.K., Alwarappan S., Yoshimura, M., Sahajwalla, V., Nishina, Y., Appl. Mater. Today, 1, 1-12 (2015)

8. Yan, L., Li, Y., Xiang, C., Xianda, S., J. Membr. Sci., 276, 1-2 (2006)

9. Li X., Pang R., Li J., Sun X., Shen J., Han W., Wang L., Desalination, 324, 48-56 (2013)

10. Kebria M.R.S., Jahanshahi M., Rahimpour A., Desalination, 367, 255-264 (2015)

11. Méricq J.P., Mendret J., Brosillon S., Faur C., Chem. Eng. Sci., 123, 283-291 (2015)

12. Wang Q., Wang Z., Zhang J., Wang J., Wu Z., RSC Adv., 4, 9 (2014)

13. Bacchin, P., Aimar P., Field R., J. Membr. Sci., 281, 1-2 (2006).

14. Field R.W., Wu D., Howell J.A., Gupta B.B., J. Membr. Sci., 100, 259-272 (1995)

15. Pierre L.C., Bruce J., Chang I.S, Judd S.J., J. Membr. Sci., 227, 1-2 (2003)

16. Maruf, S.H., Greemberg A.R., Pellegrino J., Ding Y., J. Membr. Sci., 471, 65-71 (2014)

17. Zhang Y.P., Law A.W.K., Fane A.G., J. Membr. Sci., 365, 1-2 (2010)

18. Wei C.H., Huang X., Aim R.B., Yamamoto K., Amy G., Water Res., 45, 2 (2011)

19. Tanudjaja H.J.,Pee W., Fane A.G., Chew J.W., J. Membr. Sci., 513, 101-107 (2016)

20. Xie W., Li J., Sun F., Dong W., Environ. Sci. Pollut. Res., (to be published).

21. Perry V.D.M., Arie A., Antoine K., Matthias W., Hardy T., Walter V.D.M., J. Membr. Sci., 332, 1-2 (2009)

22. Xie W., Li J., Sun T., Shang W., Dong W., Li M., Sun F., Environ. Sci. Pollut. Res., 25, 25 (2018)

23. Espinasse B., Bacchin P., Aimar P., Desalination, 146, 91-96 (2002) 